\title{
ELS DISCURSOS FUNDACIONALS SOBRE EL CATALÀ
}

\author{
FOUNDATIONAL DISCOURSES \\ ON CATALAN LANGUAGE
}

\section{Francesc Feliu \\ Institut de Llengua i Cultura Catalanes - Universitat de Girona \\ francesc.feliu@udg.edu}

Resum: S'intenta traçar una perspectiva general, a partir dels principals aspectes que hi prenen part, dels discursos sobre l'origen i l'aparició de la llengua catalana que s'han proposat d'ençà que hi ha hagut treballs de reflexió històrica sobre aquesta llengua. Sense pretendre l'exhaustivitat, se citen autors i obres sols amb la intenció d'illlustrar els diferents posicionaments.

Paraules clau: origen lingüístic, llengua catalana, narració històrica, idees lingüístiques.

Abstract: This paper attempts to draw a general perspective, from the main aspects that take part in them, of the discourses on the origin and the appearance of Catalan language that have been proposed since there has been works of historical reflection on this language. Without claiming to be exhaustive, authors and works are cited only with the intention of illustrating the different positions.

Key words: Linguistic beginning, Catalan language, historical narrative, linguistic ideas. 
Francesc Feliu

Els discursos fundacionals sobre el català

En aquest breu treball voldré traçar una perspectiva general dels diferents discursos sobre l'origen de la llengua catalana que s'han concebut, s'han elaborat i s'han difós, per part dels estudiosos, al llarg de la història d'aquesta llengua. No ha estat pas habitual el tractament neutral — potser seria millor dir-ne escèptic — de les diferents teories existents, ja que els filòlegs, quan ens hem ocupat d'aquestes qüestions, hem tendit a contraposar les idees més o menys desviades d'un text o d'un autor amb l'explicació real, donant per fet un partit pres. La consideració conjunta de tot aquest seguit d'hipòtesis, de vegades obertament contraposades, de vegades diferenciades sols per matisos, permet d'aproximar-nos de manera eficaç a la naturalesa discursiva del treball dels filòlegs, i posa al descobert la càrrega ideològica que de forma inevitable acompanya les certeses científiques en el nostre camp.

Naturalment, l'objectiu d'aquest treball respon a la convicció que els discursos, més o menys científics, sobre les llengües són una part fonamental d'allò que hem d'estudiar quan volem fer història de la llengua (Nicolás 1998), i parteix inevitablement de la consideració que les llengües no són pas objectes naturals i objectivables, sinó objectes complexos, en part naturals i en part culturals, modelats en bona mesura pels homes que les parlen, en funció de llurs interessos o possibilitats. Es podria pensar que aquest posicionament cau en el «pecat» del relativisme, però com ha afirmat encertadament Jordi Ginebra en un treball recent, «la feina del lingüista, de l'historiador de la llengua, del sociolingüista, és analitzar i desconstruir la realitat social de la llengua, que no estava predeterminada per la força de la natura i que podia haver-se configurat de moltes maneres, per tant; però que s'ha configurat d'una manera, i no d'una altra» (Ginebra 202I). És cert, seguint encara el raonament de Ginebra, que «dir que la realitat és contingent no vol dir que sigui elàstica, reversible ni estocàstica. $\mathrm{Ni}$ que depengui exclusivament de la mirada de l'estudiós», però "la mirada de l'estudiós" condiciona, sens dubte, les certeses socialment compartides i la percepció que de la pròpia llengua poden tenir els seus parlants. Per això cal avançar, com ha reclamat Miquel Nicolás (20II: II3), cap a «unes noves formes de reconstruir la història plural de la llengua que se centrin en l'explicació, i dins les quals l'historiador conjumini la legítima convicció nacional (i nacionalista) amb la consciència crítica i la distància inherent a l'observació participant». 
Francesc Feliu

Els discursos fundacionals sobre el català

\section{ALGUNES CONSIDERACIONS PRÈVIES}

1. L'antiguitat, que inclou la idea de la continuïtat en el temps o perdurabilitat, ${ }^{1}$ és un dels pressupòsits fonamentals per a l'existència mateixa de qualsevol llengua (Feliu 2019; Feliu, Nadal \& Ferrer 202I). En realitat, la finalitat última de la filologia —no sols de la història de la llengua - és acreditar l'antiguitat de la llengua de què s'ocupa, i la seva trajectòria continuada en el temps, perquè és justament això el que legitima l'existència efectiva d'una llengua. Editant textos literaris i no, estudiant-ne el context o estudiant la llengua d'aquests textos —només tenim textos, de les èpoques pretèrites_ - s'acredita que la llengua fa molt temps que existeix, i es posa de manifest que es tracta d'una realitat externa als individus que ara l'usen, que va molt més enllà de la seva (la nostra) existència. La ciència lingüística moderna, i la romanística especialment, van tenir també aquest principi motor des dels seus orígens, en el context d'una ideologia romàntica que cercava l'afirmació nacional a partir dels atributs col-lectius intemporals, entre els quals excel-lien les llengües.

La fundació de la llengua va estretament lligada a la idea de l'antiguitat, i vindria a ser la circumstància concreta amb què s'inicia l'existència de la llengua en un temps antic. Segons quina sigui aquesta circumstància, la naturalesa de la llengua antiga serà una o una altra. Per exemple, si la fundació de la llengua esdevé pel fet que la corrupció lingüística d'una llengua oral prèvia arriba a fer-la incomprensible per als que la parlen rectament, la naturalesa de la llengua primitiva serà caòtica, irregular, mancada; si l'origen fos, en canvi, en una decisió divina, la llengua més antiga serà ja una llengua perfectament estructurada, completa, autosuficient. Si es tracta d'una llengua transportada des d'un altre lloc, trigarà un temps a prendre una fesomia pròpia, però seria ja també des de l'origen una llengua estructurada, etc. La fixació del relat fundacional, aquesta sí, ha estat sempre una competència dels historiadors o erudits que han pogut especular amb les dates i les dades relatives a l'origen; en temps més recents, els historiadors de la llengua hem assumit directament aquesta comesa, que constitueix sens dubte un dels principals objectius del nostre treball.

2. El relat fundacional està condicionat, inevitablement, per la idea de llengua —d'allò que és la llengua — que s'ha establert amb posterioritat. És a dir, pels límits

I. El mot perdurable, que Alcover, per exemple, aplica sovint a la llengua, incorpora a més una idea de perennitat (per al $D C V B$, perdurable és 'Que dura per sempre'): "que'ls nostres inimichs no tenguen altre remey qu'acalar el cap o fogir devant el llampeguetx enlluernador del reynat de la nostra gramàtica, indestructible y perdurable, dins el camp de les nostres lletres» (Alcover 1908: 399). Del perennialisme en la llengua n'ha parlat Josep Maria Nadal (2005: I05-I07).

Caplletra 71 (Tardor, 2021), p. 175-200 
Francesc Feliu

Els discursos fundacionals sobre el català

territorials que s'ha decidit que té la llengua, per les afinitats definides i per les dissociacions volgudes, per exemple en la tria de solucions gramaticals o lèxiques respecte d'alguna llengua veïna que n'hagi interferit històricament el desenvolupament. Els historiadors de la llengua seleccionem, com si es tractés d'aquella selecció de records que fem habitualment els humans a mesura que ens fem grans per explicar i donar sentit a la pròpia vida, els fets que resulten rellevants en la conformació de la llengua i els que no, els materials lingüístics que són fiables per documentar la llengua primitiva i els que no ho són, els llocs on es pot trobar el rastre de la llengua i els que queden al marge de la genuïnitat.

Cal advertir, però, que de vegades la idea d'allò que és la llengua s'ha definit — potser, perquè s'ha hagut de re-definir — molt tardanament, sigui per causa d'una insuficient projecció cultural durant determinades èpoques, per la resolució eventual de certs conflictes històrics, o per l'absència dels atributs polítics que al capdavall afermen l'estatus de la llengua. El català — com passa amb moltes altres llengües europees que no han tingut un estat nacional al darrere- és un dels casos en què hi ha hagut una indefinició substancial considerable durant segles: ha estat tingut per una varietat de la gran llengua «provençal», per un dialecte espanyol o per una llengua autònoma, i s'ha restringit als límits estrictes de l'entitat política que li dona el nom, o s'ha estès a més o a menys dels seus antics dominis. En aquests casos, el discurs històric i el relat fundacional que en forma part, ni que fossin sols incipients, s'han hagut de refer ocasionalment per adequar-los als interessos i a les possibilitats de la comunitat que es vol representada en la llengua. Per això resulta especialment interessant revisitar tota una colla de testimonis que, encara que són ben coneguts, evidencien en el contrast l'evolució històrica del discurs sobre la pròpia llengua.

3. He desistit de fer la distinció que d'entrada es podria esperar entre relats purament mítics, $o$ incontrastables, i relats pròpiament científics i objectius, perquè aquesta, precisament, és una distinció problemàtica i enganyosa: la ciència lingüística, ni que sigui la més acurada, en la mesura que selecciona les dades per analitzar no pot atènyer mai l'objectivitat absoluta $i$, en la mesura que elabora una narració sobre un origen que és hipotètic per definició, és també mítica (Feliu 20I4, esp. I38-I40; Victorri 2006). D’altra banda, cal recordar que els mites són també, d'alguna manera, part de la realitat: es construeixen a partir de fragments de realitat i, sobretot, esdevenen realitat en la mesura que són percebuts com a reals en un àmbit que és el terreny de les idees; transmeten, llavors, la idea real de la llengua que tenen els «experts» de cada moment històric. Per dir-ho amb paraules afortunades de Miquel Nicolás (1998: 302), «la història del català, i segurament la de qualsevol llengua, és mite i logos alhora, amalgama de components emotius i d'interpretació racional». 
Francesc Feliu

És per això que he cregut més adequat organitzar a l'entorn d'alguns eixos temàtics, encara que siguin interdependents i que en part se sobreposin els uns als altres, els diferents plantejaments recollits sobre l'origen de la llengua catalana; discursos fundacionals que s'han expressat en diferents èpoques i per part d'autors diversos, amb perspectives i interessos divergents.

\section{LA LLENGUA D’ORIGEN}

La posició més àmpliament compartida, pel que fa al'origen del català, és situar-lo en una altra llengua anterior. Les disquisicions sobre els orígens del llenguatge humà han tingut una llarga tradició, com és sabut, i la gran majoria de les especulacions sobre l'origen de les diferents llengües — potser llevat de l'hebreu, que en ser la llengua vehicular de les parts més antigues de la Bíblia és tingut sovint per la llengua primigènia, instituïda per Déu - assumeixen la idea de la derivació o filiació entre llengües. La posició oposada podem documentar-la, però, en la interessant dissertació sobre l'origen i formació de la llengua que encapçala la Historia de la lengua y de la literatura catalana, desde su origen hasta nuestros dias, de Magí Pers i Ramona, on s'afirma que

\footnotetext{
Dios quiso que el hombre comunicase libremente con sus semejantes; por lo mismo le organizó de modo que por sí solo pudiera con el tiempo formarse una lengua con la cual pudiese manifestar sus pensamientos y desenvolver sus ideas. Buscar otro orígen á las infinitas lenguas que conocemos, es perder el tiempo lastimosamente. [...] queda demostrado que las lenguas nacen con los pueblos, viven con ellos y mueren cuando estos dejan de existir; y que es errónea la idea de que en las lenguas hay madres é hijas, primitivas y derivadas; y mucho menos que unas se formen de otras (Pers i Ramona I854: I4-I5)
}

L'erudit vilanoví, fent valdre també els seus coneixements de frenologia, ${ }^{2}$ argumenta en definitiva que els aborígens que poblaren originàriament el territori català van generar també la llengua que, malgrat els abundants canvis soferts amb el temps per la influència dels diferents pobles amb què tindrà contacte, es manté essencialment la mateixa, no havent-hi hagut mai solució de continuïtat. Encara que aquest raonament pugui semblar-nos extravagant, les intuïcions de Magí Pers, despullades de la retòrica i l'estil vuitcentista, no s'haurien de menystenir alegrement; la seva idea que la llengua és sempre canviant però sempre la mateixa —i que el que canvia, si de cas,

2. Pers fou amic i deixeble del malgratenc Marià Cubí, personatge inquiet i pintoresc com Pers mateix, i introductor de la frenologia a Espanya. Cubí també es va interessar per la lingüística i la literatura, però les obres que va dedicar-hi es referiren exclusivament a l'espanyol.

Caplletra 71 (Tardor, 2021), p. 175-200 
Francesc Feliu

Els discursos fundacionals sobre el català

és el nom que s'hi dona-, o bé el seu convenciment que l'evolució de les llengües no pot orientar-se en cap cas cap a la fragmentació sinó cap a la convergència, resulten avui d'una rara i suggeridora modernitat. ${ }^{3}$

Sigui com sigui, la major part dels erudits de tots els temps han volgut que la llengua catalana «neixi» d'una altra llengua anterior. Aquí cal fer una distinció forta entre els discursos que pressuposen un origen en el llatí, i els que conjecturen l'origen del català en una altra llengua que no és el llatí. No hi ha una successió temporal dels diferents supòsits, i de fet conviuen o se sobreposen en el temps. La teoria de l'origen llatí és la més estesa, però hauríem d'anar en compte de no atribuir massa simplement les propostes d'un origen no llatí al desconeixement o a la desorientació. La vinculació entre el llatí i el català -que durant molt temps és anomenat també vulgar, pla o romanç, adjectius que al.ludeixen inevitablement a la llengua de l'alta cultura- és molt antiga i ha estat evident per a qualsevol persona lletrada sempre. Cal, per tant, anar més enllà i pensar per què alguns autors han proposat un origen no llatí, quin sentit tenien les seves propostes, i com les hem de llegir.

Alguns eclesiàstics per exemple, al tombant dels segles XVII i XVIII, propugnen la hipòtesi que el català és una de les setanta-dues llengües en què Déu va dividir la llengua primigènia en l'episodi de Babel ${ }^{4}$ —és el cas del valencià Vicent Marés, rector de Xelva, o del frare barceloní Agustí Eura, autor d'una Controvèrsia sobre la perfecció del llenguatge català. Pep Valsalobre, a propòsit dels textos apologètics d'Eura, ha explicat que s'han de llegir, precisament, tenint en compte que la seva finalitat no és pròpiament filològica o historiogràfica, sinó apologètica, i que per això estan escrits des d'una perspectiva mítica; s'hi utilitza conscientment el mite babèlic i se supedita a una intenció ideològica, que és la vindicació de la llengua catalana (Valsalobre 2002: I36-139).

Un altre autor que proposa un origen semític per a la llengua catalana és el filòleg Marià Grandia, que en la seva Gramàtica etimològica catalana desenvolupa una teoria bastant original que fa derivar successivament, una de l'altra, totes les llengües que han tingut segons ell presència en el territori català. La idea de Grandia —que basteix

3. El dia que tanco la redacció d'aquest treball llegeixo encara amb sorpresa, en un article de divulgació a la premsa que signa un professor de la Universitat de Barcelona, que «les llengües no són més o menys antigues. El que és més o menys antic són els noms de les llengües, que ho són perquè es corresponen amb la consciència dels parlants» (Comellas 2020). Tant d'això com de l'altra qüestió —fragmentació/convergència— en parlaré més avall.

4. Sobre la vinculació de l'origen de les llengües amb l'episodi babèlic, molt estesa a Europa a partir del segle Xvı, i sobre les diferents interpretacions del mite de Babel al llarg de la història, cal consultar l'extensa obra de Borst (I957-I963). 
significativament, com a introducció a la seva obra, una "Història de la llengua a Catalunya» i no pas una història de la llengua catalana_- en realitat s'assembla molt a la que ja hem vist en Pers i Ramona, només que per a Grandia la llengua dels pobladors antics no és una llengua autogenerada, sinó que «es en el fondo l'hebrèa, tirant, ens sèmbla, a aramèa» (Grandia I90I: XVII). Les llengües que hi ha tingut contacte amb el pas del temps, i el llatí entre elles, l'han pogut influir, però no pas substituir: ${ }^{5}$

Es molt comú crèure que'l català es fill natural del llatí, mentres que sòls n'es fill adoptiu; volèm dir que la llèngua llatina y també la grega, còm a llèngues de la civilisació, donaren un impuls i una direcció tan forta a les llèngues dels pòbles que civilisaren que se les afillaren fins al punt de ferles pèndre per filles seves. Però'ls estudis històrichs han demostrat ab ajuda de la filologia que dites llèngues tenien el seu ser. Existien ja mènos riques de formes, però mes abundants d'arrèls que la llatina, y sobretot mès senzilles. La llèngua llatina s'aná separant de la capacitat del pòble per quedarse la llèngua de la política, de l'oratòria y de la poesía, que no era vulgar còm la nòstra sinó clássica. Les llèngues populars, al contrari, guardaren la senzillèsa y nuhèsa de l'arrèl semítica o indiana (Grandia I90I: XXIII)

Trobem un plantejament molt semblant entre els apunts, encara inèdits, per a una monografia sobre el català del Rosselló, que va deixar el sacerdot perpinyanès Jean Sarrete (I868-I948); ${ }^{6}$ en aquest cas però, atès l'univers mental francès en què va viure, la llengua d'origen és el gal, és a dir, la llengua cèltica pròpia dels habitants de l'antiga Gàl.lia:

La langue catalane n'est pas fille du latin, mais du français (c'est a dire, du gaulois). Elle n'est qu'apparentée au latin, qui n'est qu'une langue moderne née au ier siècle de l'ère romaine des idiomes italiotes qui l'entonaient.[...] La langue gauloise n'est pas celle que l'on parle aujourd'hui, ni celle du Moyen Age [...] toutes les vieilles langues de l'Empire Romain sont encore vivantes, lui seul a disparu, malgré son triple privilège d'être une grande langue littéraire, d'avoir été pendant plus de 1500 ans la langue officielle et internationale de l'Europe et d'être resté la langue religieuse de la chrétienté, ce qui seul aurait dû suffire pour assurer son éternité.

Aquests plantejaments, o altres de semblants, encara els sostenen avui algunes persones - no cal dir que del tot a contracorrent, al marge completament del'Acadèmia i de manera quasi clandestina (vegeu Cortez 2007, o Jiménez 2016); no és el propòsit d'aquest treball discutir o acreditar unes o altres teories, però hem d'admetre que el

5. A més, com assenyala amb certa perspicàcia, la influència del llatí no hauria de situar-se necessàriament a l'època de la dominació romana: «La llatinisació romana del Catalá es en part aparent, y en la part real es deguda bòn xich als temps posteriors a la dominació de Roma» (Grandia I90I: xxiii)

6. Sembla que els papers de Sarrete, entre els quals aquests esborranys que he esmentat, van ser dipositats per l'eminent biblista Maties Delcor, que havia estat deixeble seu, a l'Arxiu Departamental dels Pirineus Orientals, on romanen encara. L'edició d'aquests materials és encara pendent de fer. Sobre l'obra d'aquest erudit vegeu Delcor (1985). 
Francesc Feliu

Els discursos fundacionals sobre el català

punt més feble de la hipòtesi de l'evolució llatina és el seu punt de partida: l'adopció del llatí com a llengua d'ús habitual per part de tota la població, ni que fos un procés gradual, té gaire sentit imaginar-la en uns termes anàlegs als dels processos de substitució lingüística que han descrit els sociolingüistes moderns? En contextos purament orals, en absència de referents normatius de cap mena per a un llatí «vulgar» que hem convingut que és la llengua de la qual deriven totes les romàniques, sense consciència lingüística possible per part de la immensa majoria dels parlants, sense una pressió demogràfica significativa per part dels colonitzadors, es pot produir una assimilació lingüística tan homogènia?

Lorigen llatí, tant se val, ha conciliat sempre la major part de les opinions —aquí, com arreu de l'àmbit «romànic»—, i ha esdevingut l'element nuclear del discurs fundacional hegemònic. Hi ha, però, una variant que ens cal considerar: la que assumeix l'origen llatí, però per llengua interposada. Aquesta idea, que ha tingut entre els historiadors i filòlegs catalans, al llarg del temps, una important i persistent atenció, té al seu torn dues possibles concrecions: la teoria que en podríem dir llemosinista, i la que suposa l'existència de la llengua romana. Ateses les característiques d'aquest treball, descarto d'entrar en gaires detalls sobre les propostes i els matisos particulars dels nombrosos autors que han tractat el tema, encara que val la pena notar que en la majoria dels textos - fins en alguns de prou recents - hi constatem uns nivells d'imprecisió i d'ambigüitat molt elevats.

La idea que el català ve d'una llengua (neollatina) anterior, més antiga, que seria el llemosí, és força freqüent entre els erudits des del renaixement. Ha estat ja prou estudiat el fenomen de les «traduccions» de textos medievals — pretesament escrits en llengua llemosina - a l'hora de preparar-ne edicions impreses (Fuster 1984, Schmid 1988, etc.), que en realitat té a veure amb el procés, prou general, de distanciament envers els models lingüístics, estètics i formals de les llengües vulgars medievals per part dels intel-lectuals moderns (Nadal I992c, Ferrando 2000, Rafanell 2000). L'ús del designador llemosí, encara que amb aplicacions diverses, va fer fortuna i fou abundant fins ben entrat el segle XIx (Rafanell I99Ia i I99ib). Però pel que fa a la reflexió sobre l'origen i naturalesa d'aquesta llengua "prèvia», que se sol identificar amb la llengua dels documents més antics i/o amb la de la literatura trobadoresca, el precedent més clar és l'historiador barceloní Francesc Calça, que en el seu tractat De Catalonia (I588) la identifica amb la llengua dels llemosins d'Aquitània — que no és pas el provençal ni cap altra parla occitana (f. 75v-76r.) —, una llengua que els aquitans catalàunics ${ }^{7}$

7. Tota l'argumentació històrica de Calça en el seu llibre parteix de la identificació com a «aquitans» dels antics habitants dels Camps Catalàunics (a l'entorn de l'actual ciutat de Châlons en Champagne, on s'hi 
Francesc FeLiu

Els discursos fundacionals sobre el català

haurien trasplantat a Catalunya en una emigració subsegüent a la conquesta franca, i que s'hauria mantingut amb més puresa en la zona de l'Empordà, on la densitat demogràfica dels repobladors llemosins hauria estat més alta.

El jurista perpinyanès Andreu Bosc, quaranta anys més tard, subscriu encara aquesta teoria, però l'historiador valencià contemporani Gaspar Escolano, en canvi, considera que el llemosí és en realitat una barreja de la llengua dels hispans que van fugir de la invasió àrab i la dels «francesos» de la zona de Llemotges, i que és la llengua que encara es parla a Catalunya coetània. Amb el temps, d'aquest català o llemosí, degudament llimat i depurat i prenent noves paraules del llatí, en sortirà la llengua valenciana. ${ }^{8}$ Carles Ros, ben entrat el segle XviıI, reformula lleugerament aquesta hipòtesi i fa, en realitat, una síntesi de les dues idees: la llengua catalana i la valenciana "una y otra salieron de la limosina», però la catalana — «comprehendiendose en la de Cataluña, la de Mallorca, Menorca, è Ivìsa» — amb prou feines ha evolucionat, i «se conserva mal sonante, grossera, isleña, y montaràz; que à esto llamamos los valencianos margall»; l'altra, naturament, "tuveron mańa los valencianos para limarla y ponerla en mayores realces» (Ros I734: I8-2I). El llemosí resulta, en definitiva, per a molts erudits catalans i valencians del XVI al XIX un pas intermedi entre el llatí i la llengua contemporània, encara que amb caracteritzacions i delimitacions temporals diverses.

En aquest sentit, el «llemosinisme» fa un plantejament que té punts de contacte amb les especulacions dels protoromanistes europeus, que va recollir i difondre per primera vegada al nostre país el canonge gironí Antoni de Bastero, sobretot en el volum que havia d'encapçalar la seva Crusca provenzale (I724). Les especulacions a què em refereixo passen per imaginar l'existència d'una llengua romana, filla primogènita de la llatina, de la qual s'haurien derivat després tota la resta de les llengües dites

havia lliurat una famosa batalla dels romans, aliats amb els visigots, contra els huns), que en realitat se situen fora dels límits territorials que mai vagi tenir Aquitània, la qual sí que incloïa, en canvi, la ciutat de Llemotges, d'on pren nom la llengua que suposadament parlaven els catalàunics emigrats a Catalunya. La disquisició geogràfica, però, ara no ve al cas.

8. En aquest plantejament, Escolano segueix i matisa, de fet, la proposta de l'historiador cinccentista Pere Antoni Beuter, que afirmava que el català ve del francès i que, més tard, del català en sortirà el valencià, fent una formulació força més rudimentària, i estretament lligada a les legitimitats polítiques històriques i a llurs dependències legals (Rafanell I99aI: 55). Beuter és també el pare del joc de paraules «limo sin» ('sense llimar') que servirà sovint, en endavant, per connotar negativament la llengua més antiga (Fuster 1984); encara que Martí de Viciana i algun altre autor valencià de la segona meitat del Cinc-cents havien considerat que el llemosí era la llengua «barrejada» que es parlava a València, derivada de la llengua provençal que parlaven a la cort (Rafanell I99Ia: 6I-63), aquesta idea no va arrelar, ja que el nom de llengua valenciana era molt més clar i efectiu, i donava molt més joc reservar el nom de llemosí per a la identificació d'alguna fase o estadi de llengua antics.

Caplletra 71 (Tardor, 2021), p. 175-200 
Francesc Feliu

Els discursos fundacionals sobre el català

romàniques. ${ }^{9}$ Bastero no va pas ser el primer a identificar la llengua romana amb la llengua dels primers testimonis vulgars i de la poesia trobadoresca, ni molt menys va ser el primer a identificar la llengua catalana amb la dels territoris del migdia francès, coneguda llavors entre els erudits com a provençal i vinculada al patrimoni literari dels trobadors — la filiació llemosina, de fet, responia a aquesta idea. L'erudit parisenc Claude Fauchet, referint-se a l'important testimoni documental dels Juraments d'Estrasburg, afirmava ja a les darreries del segle XVI que:

On ne peut on dire que la langue de ces sermens (laquelle Guitard apelle romaine) soit vrayement romaine (j'entens latine) mais plustost pareille à celle dont usent à present les provençaux, cathalans ou ceux du Languedoc [...] Il faut donc nécessairement conclure que ceste langue romaine entendue par les soldats du roi Charles le Chauve, estoit ceste rustique romaine en laquelle Charles le Grand vouloit que les omelies preschées aux églises fussent translatées, à fin d'estre entendues par les simples gens, comme leur langue maternelle (Fauchet I58I: 28)

La lingua romana rustica a què s'apel-lava en el cèlebre cànon del concili de Tours, de l'any 8I3, prenia, doncs, entitat com a llengua materna dels súbdits de Carlemany, i la proximitat objectiva d'aquesta llengua amb la dels occitans lato sensu permetia la identificació de la llengua d'aquests amb la dels primers testimonis romànics $i$, en conseqüència, amb la dels antics trobadors — força més estranya. ${ }^{10}$

De tot això en parteix, en realitat, la ciència romanística moderna, que té en el provençal François Raynouard el primer baluard seriós. ${ }^{11}$ Raynouard, a banda de diverses antologies de poesies trobadoresques, elaborà gramàtiques de la llengua romana i també un diccionari —el Lexique roman ou dictionnaire de la langue des troubadours, en 6 volums, acabat el I844- considerat encara avui de referència inexcusable per a l'estudi dels trobadors (Vàrvaro I988: 34). Al territoris de cultura catalana, després de Bastero - però abans de Raynouard - difongueren la hipòtesi de l'existència de la llengua romana alguns erudits, el més rellevant dels quals és Josep de Mora, marquès de Llió, que publicà un «Apéndice al lenguaje romano vulgar» dins les seves volu-

9. O, almenys, bona part d'elles. L'italià o toscà, essent també llengua pròpiament «romana» (del territori originari dels romans), té per part d'alguns autors la consideració de "germana menor» de la llengua romana, però filla directa també de la llatina (Bastero I724: 54-55 i 69-70).

Io. Encara avui es considera generalment que la llengua en què escrigueren els trobadors fou l'occità, una llengua definida i delimitada, de fet, en èpoques molt posteriors. Tanmateix, la distància lingüística entre el codi trobadoresc i les varietats vives parlades — i escrites! (per exemple, en els textos en prosa) — al migdia francès és més que notable. En canvi, resulta evident que els juraments son encara avui prou comprensibles per a un catalanoparlant mínimament familiaritzat amb la llengua dels monuments antics (Moran \& Rabella 200I: 15-I6). II. Sembla que és a partir de la lectura de les obres de Raynouard que Friedrich Diez, per indicació de Goethe, va dedicar-se a l'estudi de les obres dels trobadors i a la comparació gramatical de les varietats romàniques, iniciant així la ciència lingüística del nostre temps (Vàrvaro 1988: 45 i s.) 
minoses Observaciones sobre los principios elementales de la Historia (I756). ${ }^{12}$ La teoria de la preeminència del català entre les llengües romàniques va aparèixer amb certa freqüència i de forma més o menys velada en discursos i tractats sobre la història de la nostra llengua mentre no va caldre dilucidar definitivament la qüestió de la identitat amb la llengua dels trobadors; a partir del moment en què va establir-se una distinció clara entre el català i l'occità (Rafanell 2006: 44I i s.) la hipòtesi de la llengua romana va decaure definitivament entre els estudiosos del català.

Tanmateix, i en certa manera, hi ha un episodi que ens acosta fins als nostres dies el debat sobre l'esglaó intermedi entre el llatí i el català. Em refereixo a la coneguda polèmica a propòsit de la dita «subagrupació romànica» del català, que parteix de la classificació, per part de Meyer-Lübke (1925), del català com a llengua gal-loromànica. En els termes en què es planteja, la discussió pressuposa en definitiva l'existència d'un llatí gàl-lic i d'un llatí ibèric —o latín español, per dir-ho a la manera de Menéndez Pidal- previ al naixement del català i de les llengües veïnes. ${ }^{13}$ Com és sabut, l'enfrontament entre lingüistes sobre aquesta qüestió es va resoldre sols a mitges, a partir de les contribucions d'Antoni Maria Badia (1955) i de Germà Colón (1976) que, en qualsevol cas, no impugnen pas clarament l'existència d'uns estadis lingüístics, postllatins i preromànics, relativament homogenis i diferenciats entre ells. ${ }^{14}$

\section{EL LLOC I EL MOMENT. ELS PRIMERS TEXTOS}

La localització espaciotemporal de l'origen de la llengua és una preocupació que tradicionalment han manifestat la majoria dels estudiosos quan han volgut explicar els inicis de la llengua, ja que constitueix una part substancial del relat fundacional. Tanmateix, la qüestió cronològica — l'antiguitat— és la que ha anat acaparant cada vegada més, amb el pas del temps, l'atenció dels especialistes, en detriment de la qüestió del lloc; la majoria dels manuals i estudis més recents passen de puntetes damunt

I2. Pers i Ramona, en el text citat abans, recorre també a la idea de la llengua romana, però en fa una apropiació singular, ja que la considera una llengua diferent i anterior al llatí (1854: 47-48).

I3. No és aquest el lloc per resseguir els detalls de la polèmica, que implica noms importants de la romanística del del segle xx com Ramón Menéndez Pidal, Amado Alonso o Gerhard Rohlfs. Hans-Ingo Radatz (20I2) n'ha fet una síntesi recent, i ha revisat els termes del debat.

I4. Els conceptes iberoromània i gal-loromània són usats avui normalment entre els especialistes, i no són pas qüestionats - Ethnologue, per exemple, els utilitza en la seva classificació de les llengües; com a màxim s'admet que el català encaixa amb dificultats en la classificació, «having been subject for centuries to alternating Occitan and Spanish influences» (Green 1990: 196) 
Francesc Feliu

Els discursos fundacionals sobre el català

d'aquest l'assumpte, i fins podrien donar a entendre que el domini lingüístic actual és el que sempre ha tingut la llengua, que la llengua és en el lloc on ha estat sempre d'ençà que existeix, ${ }^{15}$ quan és obvi que això no és així. La ideologia lingüística nacional és segurament la principal responsable d'aquest "oblit», així com també de l'interès redoblat entre els lingüistes per argumentar i justificar una data d'origen com més antiga millor.

Però deturem-nos un moment en el tractament que ha tingut en el passat la qüestió del lloc on s'origina la llengua. Naturalment, els autors que proposen una generació autòctona o un origen lingüístic de caràcter immemorial no concreten el lloc on va originar-se la llengua, perquè pressuposen que va originar-se arreu on es parla. Però en conseqüència amb aquest plantejament han de negar la possibilitat que una llengua pugui estendre's cap a nous territoris si ja eren poblats, és a dir, que es puguin produir processos de substitució lingüística:

Otro error y no pequeño ha sido el haber asentado algunos inconsideradamente que los conquistadores podian matar ó bien sufocar la lengua de los pueblos sometidos, imponiéndoles la suya. Los pueblos, así como las lenguas, sometidas al dominio de otros pueblos, pueden hacerse acallar, adormecer por un tiempo si se quiere, pero no matarlas. Para ello fuera preciso que los conquistadores, al someter un pueblo bajo su imperio, acabáran con todos los habitantes conquistados; esto es, que no quedara raza alguna de aquel pueblo, puesto que los nuevos habitantes serian entonces los conquistadores mismos. De otro modo, no, y mil veces no (Pers i Ramona 1854: 43)

Per això, Marià Grandia afirma en la seva seva gramàtica que

\footnotetext{
No podèm avenirnos ab l'opinió comuna que consigna el P. Nonell [...] dihent que «a les Balears y a Valencia hi fou transportada (la llèngua catalana) de Catalunya pels conqueridors d'aquèlls règnes que s'hi establiren" [...] Nosaltres creyèm que'l catalá a les Balears y Valencia s'hi desenrotllá espontániament y ensemps que a Catalunya, còm ensemps se desenrotllaven en Itália 'l piemontès, milanès y bolonyès que tants punts de contacte tenen ab la llèngua catalana (Grandia I90I: xxxIV)
}

Un raonament que no podrien subscriure, amb tot, els partidaris que el valencià o el balear són llengües romàniques autònomes, perquè recolza en la idea essencialista de l'existència de la nació subjacent, que fa que d'una manera espontània l'idioma desenvolupat arreu esdevingui el mateix idioma. Justament, els defensors de la llengua valenciana i de la llengua balear han de recórrer generalment a una altra estratègia

I5. Només d'iniciar l'estudi introductori al seu llibret sobre Elsprimers textos de la llengua catalana, Moran \& Rabella llancen la següent afirmació, sense més matisos: «El català, com totes les llengües romàniques, va néixer com a conseqüència de l'evolució del llatí local» (200I: I3) 
argumentativa, a la pervivència del mossàrab —el llatí local, sota la dominació àrab—, per poder argumentar l'alteritat lingüística de les varietats autòctones (Ubieto I979, Mourelle de Lema 1982, Cañellas 20I8, etc.). El mossàrab — tan estudiat, valorat i vindicat per estudiosos com Coromines o Sanchis Guarner- és el que fa possible la continuïtat històrica del llatí local, i permet situar el punt d'origen de la «llengua» en un lloc i un temps fora de discussió: la romanització autòctona. ${ }^{16}$

Això que acabem de constatar ens confirma, d'altra banda, que l'abast territorial que pressuposem a la llengua condiciona enormement, en el discurs fundacional, la localització espaciotemporal del seu origen. Tots els autors que, amb més o menys indefinició, han imaginat, almenys en origen, una gran llengua catalanooccitana — quasi tots, de fet, fins a la darrera centúria — han situat el lloc d'origen en alguna zona de la Gàl-lia meridional, i en tot cas han mirat d'assegurar un cert protagonisme als antics comtats catalans. Els partidaris de la derivació d'un antic llemosí —independentment de la continuïtat que li suposin —, han de situar l'origen d'aquesta llengua a la Gàllia Aquitana, on hi ha Llemotges, i han d'explicar després la seva translació: ja hem vist que Calça instal.la els catalàunics aquitans a l'Empordà arran de la campanya carolíngia; Escolano els fa fer un periple una mica més llarg, per justificar també de passada el nom de provençal:

Tuvo esta lengua su nacimiento y nombre de una ciudad de Francia, que en tiempo de romanos fue llamada Lemonices, y en el nuestro Limogenes, y la provincia Limos. [...] Criose esta apazible lengua en sus primeros pañales en la Provenza, quando lo de la entrada de los moros en España, y andando con el tiempo de mejoria el partido d.ella, como baxaron exercitos de franceses rebueltos con los antiguos españoles sus huespedes a la conquista, passo con ellos la lengua lemosina, y assi elos como ella quedaron avezindados en la primera provindcia vezina de la Francia proenzal, dando a la tierra el nuevo nombre de Cataluńa, y ella el que tiene la lengua de catalana (Escolano I6Io: c. 89 i 92)

Bastero, com la majoria dels erudits del XVIII i del XIX, amb un major criticisme i assumint la teoria de la llengua romana, situa l'origen a l'anomenada Gàl-lia Gòtica o Narbonensis (Feliu I997: 65-68), perquè és on el contacte amb la llengua dels gots, aliats dels romans, pogué transformar el llatí. Els comtats catalans, naturalment, pertanyien a la província narbonesa i això els col-loca en un punt privilegiat, encara que la discussió sobre si la llengua literària, que després s'anomenaria provençal, va conformar-se o no a la Provença gràcies al domini dels comtes catalans - i, doncs, al contacte amb la llengua que ells portaven—, ocuparà durant molt temps pàgines innumerables de tractats, dissertacions i discursos.

I6. Vegeu, sobre això, Rafanell 1993. 
Francesc Feliu

Els discursos fundacionals sobre el català

Quan, de mica en mica els estudiosos de la història del català s'instal.len en el paradigma canònic actual, segons el qual el català és una llengua romànica diferent de l'occità, ${ }^{17}$ hauran de proposar un lloc d'origen més precís, dins del territori de la Catalunya històrica. En això hi hauran d'ajudar els documents que permetin atestar la presència de la llengua, però sempre supeditats a la perimetració històrica dels antics comtats catalans - la Catalunya Vella-, que seran considerats des de llavors, per raons cronològiques, el territori constitutiu de la llengua catalana. La supeditació que acabo d'esmentar, l'explicita com poques vegades Martí de Riquer en aquell inquietant passatge de la seva història literària:

A la segona meitat del segle XI, sens dubte entre els anys I054 i I076, es compongué un poema en 593 octosíl.labs, dividits en 49 sèries monorimes, que hom titula la Cançó de Santa Fe, sobre la localització del qual els lingüistes es troben avui dia dividits en dos parers, car uns sostenen que fou escrit a la regió de Narbona i altres al Rosselló, concretament al monestir de Sant Miquel de Cuixà o al de Sant Martí del Canigó. Si això darrer es pogués comprovar de manera ferma, la Cançó de Santa Fe fóra el text literari català més antic, fins i tot anterior en un segle a l'obra dels trobadors nascuts a Catalunya (Riquer i964: 197)

Que la Cançó sigui o no un text català depèn, en definitiva, del lloc on s'escrigués, no pas del material lingüístic que la conforma. Però que el material lingüístic dels primers testimonis s'avingui amb els trets que els lingüistes consideren característics de la llengua també és necessari; en el cas curiós de les homilies contemporànies d'Organyà i de Tortosa, que comparteixen fonts i tradició comunes i tenen fins i tot un text repetit, sols les primeres són catalanes, tot i que és molt probable que les segones fossin escrites, la segona meitat del segle XII, a la recent conquerida ciutat ebrenca. Les de Tortosa són «escrites encara en provençal, però amb fragments catalanitzats» (Moran \& Rabella 200I: 3I), i les d'Organyà, segons els mateixos autors, són «la primera traducció coneguda entre llengües romàniques» (ibid.: 87).

Que la primera traducció entre llengües romàniques es produeixi precisament entre aquelles en què tothom ha vist, o bé identitat, o bé, com a mínim, «el parentiu més íntim, de bon tros» entre les romàniques (Coromines 1954: 20), no deixa de resultar sorprenent. Com sorprenent resulta també la ubicació territorial dels primers

17. Antoni de Bofarull degué ser dels primers erudits que obertament, encara que amb força imprecisions, va postular la independència lingüística del català (Ginebra I987: 20). També ho preconitzà per la mateixa època el vallespirenc Francesc Cambouliu (Bernat 2009). Abans, Pere Màrtir Anglès o Josep Pau Ballot havien iniciat aquest camí (Rafanell \& Rossich 2000). August Rafanell ha descrit amb gran detall, tant la tradició que agermanava històricament el català amb les parles occitanes, com el que ell ha anomenat «un suau procés de separació, dominat primer per un silenci espès; després consagrat pel ple divorci dels dos projectes culturals i polítics», emprès a la darreria del XIX (Rafanell 2006: 25-I33 i I35-439). 
FranCESC FeLiu

testimonis escrits, que es concentren gairebé tots en la zona dels antics comtats d'Urgell i del Pallars. Aquesta particular distribució dels primers textos catalans, que ja va ser advertida per Badia (1980), és desconcertant perquè no es correspon ni amb una major densitat demogràfica de la zona, ni amb un especial aïllament. ${ }^{18}$ Si es correspon amb alguna cosa, la localització geogràfica dels primers textos, és amb l'àrea del dialecte occidental. ${ }^{19}$ Estudiosos com Philip Rasico han abordat, per això, els trets fonològics més representatius dels parlars urgellesos medievals (1986), però manca absolutament una teoria que expliqui l'absència de textos catalans arcaics a la zona oriental, on bé que s'escrivien en vulgar, al segle XII, les poesies de Guillem de Berguedà, Guillem de Ribes, Berenguer de Palol i tants altres —incloent el rei Alfons mateix.

Sigui com sigui, el recurs als primers textos, general i compartit per totes les llengües europees des dels primers treballs prospectius, ha tingut sobretot una aplicació de caràcter cronològic; més que per determinar el lloc, serveixen per acreditar el moment del naixement de la llengua, que tothom pretén com més antic millor —i si pot ser, més antic que les llengües veïnes o competidores_, perquè de l'antiguitat de la llengua se'n desprèn legitimitat, i fins una certa transcendència. ${ }^{20}$ Bastero, a partir de les seves fonts franceses i en conseqüència amb la idea de la llengua romana, va fixar els Juraments d'Estrasburg com el primer text català, cosa que feia recular la llengua catalana als primers testimonis romànics, del segle Ix; després d'ell, molts altres autors van recollir aquesta idea fins entrat al segle Xx. ${ }^{21}$ Altres textos que reberen la consideració de "primers testimonis» han estat successivament bescantats en descobrir-se falsos — l'epitafi del comte Bernat de Septimània o, més recentment, l'acta

I8. Els comtes d'Urgell dels segles XI i XII pertanyen a la família comtal barcelonina, bisbes urgellencs com sant Ermengol tenen una fluida connexió amb els principals centres de cultura i, amb l'expansió territorial cap al sud, el comtat d'Urgell esdevindrà cap al ııoo un dels més importants del conglomerat polític protocatalà.

19. L'existència des de l'origen dels dos blocs dialectals del català va ser estudiada per Badia en un llibre (198I) que vol justificar-la per l'efecte del substrat. Les hipòtesis de naturalesa substratística per explicar la diversitat dialectal del català han estat qüestionades, però, per diversos estudiosos com Joan Veny, i el llibre de Badia fou considerat, de fet, per Josep M. Nadal \& Modest Prats com «un intent d'explicar obscurum per obscurius» (I982: 49). De fet, és força estrany que en un territori tan reduït com el domini constitutiu del català s'hi registrés una diferenciació dialectal tan marcada, tret que no l'entenguéssim com una prolongació cap al sud de la línia que separa les parles gascones de les llenguadocianes — però no tinc constància de cap proposta en aquest sentit.

20. Benedict Anderson, en el seu famós llibre sobre l'origen i la propagació del nacionalisme, s'ha referit a aquesta qüestió, i ha explicat com «efectivament, no hi ha res que ens lligui tant amb els morts com la llengua» (ap. Nadal 20I2: 8).

2I. Josep Moran (2006) ha resseguit exhaustivament totes les possibles «fonts catalanes» que han proposat diferents autors al llarg del temps. 
Francesc Feliu

Els discursos fundacionals sobre el català

de consagració de la Seu d'Urgell- ${ }^{22}$ o bé en no ajustar-se als nous criteris sobre el que és i no és la llengua catalana - ja hem vist el cas de la Cançó de Santa Fe. Amb els paràmetres d'ara mateix, els primers textos escrits en català no poden recular més enllà del segle XII, i encara amb les limitacions territorials que ja hem dit. Tanmateix, Julià Bernat Alart, en la introducció del seu important recull de documents catalans antics del Rosselló i la Cerdanya (I88I) adverteix que:

On no connaît pas de documents entièrement rédigés en catalan avant I250; mais on trouve des mots et l'orthographe de cette langue dès le Ixe siècle, des phrases entières au XI, et il serait facile d'en retrouver la syntaxe dès la même époque, sans l'enveloppe du latin, on ne peut pus irrégulier (I88I: 6)

El que Alart planteja, d'acord amb les noves tendències de la lingüística del seu temps, és molt interessant, perquè suposa la superació del marc anterior. Ja formava part generalment del discurs fundacional el raonament segons el qual la producció d'un primer text en una llengua determinada implicava que la llengua havia d'existir prèviament, però aquest lapse de temps només es podia conjecturar. ${ }^{23} \mathrm{~A}$ partir de la sistematització científica de la lingüística històrica, en canvi, es descobreix una nova via, de tipus inductiu, per a la documentació dels estadis previs a l'ús escrit de les llengües romàniques: els errors, descuits i ultracorreccions que es poden documentar en l'abundant documentació llatina dels segles anteriors a l'aparició de textos romànics — que sol ser perfectament datable i situable— permeten també atestar la llengua, abans que no se'n conegui cap text escrit. Es tracta, és clar, de seleccionar els errors significatius - els que prenen sentit en funció d'allò que considerem que serà la llengua posteriorment. I de menystenir els que no serveixen per al propòsit. Per exemple, si en un precepte del rei franc Carloman a favor de l'església de Girona, de l'any 88I, hi apareixen les paraules «in pago geronnense» en lloc de gerundense (Bastardas 1995b: II7), això permet inferir que el copista s'ha equivocat perquè en el llatí que parla habitualment el grup -nd- intervocàlic s'assimila en -nn- (pas previ a la reducció a -n-); i com que aquesta reducció sols és pròpia del català, vet aquí que podem entendre que el copista parlava ja, al segle Ix alguna mena de català, que encara no s'escrivia. Amb

22. Vegeu, respectivament, Moran (2006: I2) i Gascón \& Vergés (20I7). No ben bé entre els falsos, però sí sota l'ombra d'un dubte que mai no es podrà esvair, hi ha un primer text, perdut, que Moran ha defensat en diferents ocasions com a plausible: una frase breu escrita per un mestre de novicis en un còdex de Ripoll, que el pare Villanueva (I765-I824) deia haver vist i datava al segle x o poc més tard (Moran \& Rabella 200I: I8-I9).

23. Bastero, en la seva història de la llengua, utilitza un símil biologista i distingeix l' «origen» (engendrament) del «nacimiento» per poder inferir un temps de gestació previ a l'aparició dels primers documents, que ell proposa que sigui d'uns 200 anys (Feliu 1997: 64-70). 
Francesc FeLiu

Els discursos fundacionals sobre el català

una simple grafia —o amb un element lèxic o sintàctic — hem identificat la llengua: és el català preliterari, una veritable troballa que permet fer recular, ara sí, l'origen de la llengua fins a èpoques equiparables a qualsevol altra llengua, i que permet també separar des dels inicis el català de qualsevol altra varietat romànica, elevant determinades anècdotes a categories. ${ }^{24}$

L'estudi del català preliterari —al principi, sense aquest nom tan enginyós— va donar un nou impuls i noves perspectives per a la construcció del discurs fundacional del català. De seguida les crestomaties van poder incloure documents antiquíssims com a textos "catalans», i els lingüistes van poder abocar-se a documentar trets lèxics i gramaticals catalans en els diplomataris llatins de Catalunya que certifiquen l'existència del català molt abans que no en tinguem cap testimoni escrit. En l'antologia de Russell-Gebbet (I965) s'hi recullen una quinzena de catalan linguistic texts anteriors al segle XII, i en la més recent de Moran \& Rabella, que segueix un ordre cronològic, sols el cinquè text és, segons els autors, «redactat ja intencionadament en llengua catalana» (200I: 63). Però desvincular la naturalesa lingüística d'un text de la intenció del seu autor, sobretot en un context de continuïtat lingüística entre el llatí i el romanç — assumim l'origen llatí del romanç català- ens porta de nou cap a un terreny molt inestable, que té a veure amb la forma com imaginem el pas del llatí al català.

\section{COM S’ORIGINA LA LLENGUA}

Si la intenció de qui escriu és irrellevant a l'hora de determinar en quina llengua ha escrit els textos que, d'altra banda, són l'únic document possible de la llengua antiga, estem pressuposant en el fons que l'escriptura és un fenomen purament accidental o extern a la llengua, la qual tindria una naturalesa exclusivament oral. Això situa inevitablement el debat sobre els mecanismes o procediments pels quals es crea una nova llengua en el terreny de l'oralitat estricta. Però almenys en en cas de les llengües romàniques, com ha admès Joan Bastardas — un dels principals valedors de l'estudi del català preliterari-, aquest no és un camí gens planer, ni gens marcat:

El primer problema que se'ns presenta és el de determinar des de quin temps es parla català. [...] El problema, si es vol plantejar en termes estrictes, és insoluble perquè és ben difícil de precisar objectivament el grau de diferenciació necessària que ens permeti parlar de dues

24. La datació del català i la resta de qüestions accessòries que constitueixen el discurs canònic actual sobre la fundació del català en el context romànic es troben ben resumides a Bastardas 1995a.

Caplletra 71 (Tardor, 2021), p. 175-200 
Francesc Feliu

Els discursos fundacionals sobre el català

llengües en comptes de dos moments o de dues modalitats de la mateixa llengua (Bastardas I995b: I09-IIO)

El debat no és nou, i ens remunta de fet a les discussions renaixentistes sobre la naturalesa del vulgar, i especialment a la famosa disputa entre els humanistes Leonardo Bruni i Fabio Biondo que Josep Maria Nadal va estudiar amb deteniment (1992b). La teoria della catastrofe, encunyada per Biondo, que considerava el vulgar no pas com una varietat oral secular i paral.lela al llatí escrit, sinó com una derivació corrupta del llatí — que en el temps clàssic hauria estat parlat i escrit de forma homogènia-, va guanyar inequívocament la partida. Però és curiós constatar que no va pas imposar-se del tot entre la majoria dels erudits posteriors fins ben bé al segle XviII, quan els avenços de la filologia europea, documentant el baix llatí, abonaran aquest punt de vista. Els autors catalans i, sobretot, valencians del XvI i del XvII que aborden el tema solen atribuir certament els canvis lingüístics, o bé al contacte entre pobles de llengües diferents, o bé als efectes del pas del temps en la llengua, però ni la interferència lingüística no és considerada necessàriament negativa, ni el pas del temps no és per força contraproduent:

Formose [la llengua llemosina] del ayuntamiento de la que passaron consigo los españoles al tiempo de los moros, y de la francesa que por alli corria. D.estas dos fue engendrada, y nació tan graciosa, cortesana, sentenciosa y dulce que no hay lengua que en mas breves palabras diga mas ni mejores conceptos $[\ldots]$

Esta lengua se començo a hablar en la ciudad y reino de Valencia, y con el curso del tiempo se fue adelgazando de suerte que, arrimando algunos vocablos grosseros que hoy en dia se quedan en la catalana, poniendo en su lugar de la latina los que bastavan, acepillando los que tenian mal sonido y escabrosidad en la pronunciación y generalmente escogiendo una forma dulce de pronunciar, sin el horror i desabrimiento con que usan d.esta lengua en las provincias que la conocen por natural, ha venido a tener nombre de por si y llamarse lengua valenciana (Escolano I6ro: c. 89 i 93)

Fixem-nos, d'altra banda, en el caràcter voluntari o intencional que té tothora el canvi lingüístic en aquest tipus de relat, a banda de la valoració positiva dels efectes de la mescla lingüística. ${ }^{25}$

A partir de Bastero però, i sota l'influx dels nous corrents de la historiografia racionalista, s'imposa el relat de la corrupció:

25. El tema de la bondat de la barreja o mixtura lingüística és molt freqüent entre els autors valencians des de l'edat mitjana (Ferrando I980: 93-I32). Al Principat no és habitual, però quan Francesc Calça l'utilitza per explicar les distincions dialectals, no hi atorga un especial negatiu (Calça 1588: f. 77r/v). 


\begin{abstract}
Al paso que [...] començó a declinar el imperio romano, empezó assí mismo la lengua latina que los naturales de dichos reynos hablaban a declinar notablemente, con muchos barbarismos y solecismos que en ella insensiblemente introduxo la necessidad y precisión del comercio [...] (Feliu 1997: 63-64)
\end{abstract}

En conseqüència, les restes documentals de l'època «son casi todas escritas en latín bárbaro, de forma que el escrivir el buen latín era cosa que entonzes se tenía por milagro» (ibid.), i reflecteixen per tant una realitat caòtica, gens sistemàtica, que s'identifica amb el que devia parlar la gent. Val la pena notar, en aquest breu fragment, l'adverbi insensiblemente, que marca el canvi fonamental en els discursos fundacionals d'ençà de llavors. ${ }^{26}$ Un canvi que abraçarà tota la ciència lingüística moderna quan s'abocarà a la reconstrucció i racionalització dels processos disgregadors de les parles vulgars. La idea de la inevitabilitat de la fragmentació espontània de les llengües — un dels pilars teòrics fonamentals de la disciplina — va implícita en el paradigma de la "corrupció»; per això al segle XIX prenen també importància, al costat dels estudis diacrònics, els treballs destinats a la regularització gramatical i a la determinació de models normatius, que tenen com a objectiu la llengua escrita — no és per casualitat que comencin aparèixer tractats gramaticals i ortogràfics del català en aquesta època. I si el llatí es torna romànic sense ni adonar-se’n els mateixos usuaris, és clar que correspon als lingüistes esdevenir notaris d'aquesta transformació i pèrits de la delimitació de cada llengua: la intenció de qui escrivia un text arcaic potser no compta, però la conveniència del lingüista continuarà tenint un paper rellevant. Vegem-ne un exemple revelador, del mateix Bastardas:

No era pas llatí la llengua que parlaven els barcelonins o gironins durant l'ocupació sarraïna, ni era llatí la llengua col-loquial dels hispans exiliats a la Septimània, arran de la repressió musulmana contra els qui havien col-laborat en la fracassada expedició de Carlemany contra Saragossa l'any 778, o la llengua dels gironins que el 785 feren lliurament voluntari de llur regió a Carlemany o la dels habitants de les comarques de Cerdanya i Urgell que ho feren no gaire més tard. Una llengua romànica parlaven els barcelonins alliberats l'any 80I, i aquesta llengua romànica ja no deixarà mai d'ésser ella mateixa. Bé que oberta a influències i pressions externes, evolucionarà sobretot segons la seva pròpia dinàmica.

Ara, per la documentació coetània no en podríem pas dir res. Ni un sol tret lingüístic pertanyent al segle viII no pot ésser documentat (Bastardas I995b: III-II2)

26. La inadvertència del canvi lingüístic és assumida fins en els discursos més excèntrics, com el de mossèn Grandia: «Preguntar en quin sigle la llèngua catalana se presentá en son ésser peculiar, es igual que preguntar a un hòme quin dia's va fer gran. L'aparició d'una llèngua no es pas òbra de un sigle. El pòble que la fa aparèixer, no ho advertèx pas ell metex» (Grandia I90I: XXvi). 
Francesc Feliu

Els discursos fundacionals sobre el català

Naturalment, la detonant paradoxa d'aquest fragment és matisada després amb arguments de diversa mena, però la qüestió al capdavall és que cal refiar-se de les dades $\mathrm{i}$ les tries que, sobre un material lingüístic amorf i equívoc - $\mathrm{i}$ al marge de què pensés o volgués qui el va produir-, ha fet el lingüista.

La degradació inconscient del llatí oral local fins a un punt d'inflexió que, vist amb la perspectiva de l'estudi, marca l'inici d'una nova llengua ha estat, en definitiva, el discurs hegemònic sobre la generació del català fins a dia d'avui, en bona mesura perquè la gramàtica històrica com a disciplina no en pot prescindir per adaptar-se a un altre marc teòric. ${ }^{27} \mathrm{Hi}$ ha hagut, però, algunes excepcions. Al bell mig del segle XIX, Magí Pers impugna, des del seu particular punt de vista, la hipòtesi de la corrupció i la fragmentació, que veu contrària a l' "orden natural y progressivo de las lenguas», i proposa un dinàmica de millora contínua i de confluència:

Nada de esto ha sucedido ni es posible que suceda tampoco segun el órden natural y material de las lenguas. Solo en el hombre entra la confusión y el desórden, cuando por una de aquellas fatalidades pierde el juício; però no en las lenguas, porque no están sugetas á estas alteraciones. Entonces ¿porqué no se deja esta senda errónea, insostenible, de que las lenguas vulgares se formaron de la corrupción del latín? [...]

En vez de haber sido sufocadas las lenguas catalana, vascuence y gallega con la incorporación de Cataluña, Vizcaya y Galicia á la corona de España ha sucedido lo contrario, pues las lenguas ó dialectos de estos pueblos han ido perfeccionándose y enriqueciéndose siempre con el contacto contínuo con la lengua castellana. [...] Así es como andando los siglos esos dialectos adquirirán tal riqueza y perfección que solo se diferenciarán de la lengua general del pais en que radican en la pronunciación de algunas letras; porque en cuanto á la significacion de las palabras y en el giro de la frase serán enteramente idénticos (Pers i Ramona I856: 58-60)

Al marge de la finalitat, prou explícita, del progrés lingüístic que preveu el frenòleg vilanoví, val la pena destacar que la visió que ofereix sobre la dinàmica interna de les llengües orals resulta del tot contraposada a la idea dominant. Però la idea d'una tendència natural de les parles a convergir, contrària al principi genèric de la disgregació, serà represa en part en un nou discurs fundacional que alguns historiadors de la llengua han anat bastint en les darreres dècades.

Podríem considerar que aquest «nou» discurs té arrels també en alguns altres elements típics dels vells discursos històrics sobre el català — tant els de tirada llemo-

27. La gramàtica històrica va articular-se com a disciplina científica partint d'aquest paradigma i ha sabut conjuminar la idea de la degradació «caòtica» del sistema lingüístic llatí, amb la d'una tendència interna de les llengües a la regularitat, amb la qual cosa l'evolució de cada llengua és, en el fons, la història d'un (re) equilibrament continu del seu particular sistema lingüístic. Però no pot donar raó de l'abast — temporal o espacial— d'aquests processos de regularització: per què el llatí no podia evolucionar regularment i unit? Per què la disgregació llatina configura unes llengües i no unes altres? Per què les llengües neollatines no es fragmenten? 
Francesc FeLiu

Els discursos fundacionals sobre el català

sinista com «llenguaromanista»; en aquests s'hi tractava ineludiblement la qüestió del nom — dels noms, mes aviat — de la llengua. Sense acabar d'aclarir, moltes vegades, si es tractava o no de llengües diferents, calia esmentar i justificar tota una colla d'apellatius vinculats inequívocament amb el subjecte tractat: llemosí, provençal, català, valencià... Bastero preveu dedicar tot un capítol de la seva inacabada història de la llengua a la qüestió del nom, per aclarir

Si en el común hablar, esto es en los discursos familiares, entre nuestros antiguos catalanes la llamaban también lemosina, como hallamos que indifferentemente ambos nombres de catalana y lemosina la llaman los modernos [...] y assí mismo, si por el decurso de el tiempo desde el siglo viII, en que se llamava romana, hasta el XII, en que nació el citado Montaner, la llamaron los catalanes con otros nombres, como provenzal o lengua d'oc (Feliu 1997: I2I-I22)

Si el nom canvia — essent la llengua la mateixa — deu ser perquè «los catalanes», pel motiu que sigui, n'han tingut percepcions diferents en els diferents llocs o moments; això posa de relleu l'existència, al costat de la llengua estricta, d'una determinada consciència lingüística, d'una idea de la pròpia llengua que tenen els mateixos parlants. Aquesta constatació permet replantejar força coses, perquè en distingir «allò que un parla» de "allò que un es pensa que parla», obre la porta a un altra dimensió, de caràcter més sociolingüístic, en el raonament sobre el naixement de les llengües.

El tercer element que voldrà tenir en compte aquest discurs fundacional «alternatiu» és la relació, sempre equívoca, entre la llengua oral i l'escrita. Més concretament, aquest discurs incorpora l'escriptura com un instrument fonamental per a la història de qualsevol llengua, perquè permet de construir-ne una representació determinada, que transforma la relació dels individus amb la pròpia llengua, i que es converteix ràpidament en "la llengua» per antonomàsia —més que no pas cap varietat oral espontània. Alguns erudits ja havien intuït, antigament, la capacitat de transformació lingüística que podien tenir les convencions escrites; en la coneguda dedicatòria del seu llibre sobre la història de València, Marc Antoni Ortí hi fa referència:

Perque yo so de parer de que en estos temps lo mateix seria, parlant en valencià, dir llur, jatsia, celleshores i altres vocables antichs, que si parlant en castellà diguessem maguer, yantar, fincar de hinojos i altres; que tambe la nostra llengua, ab lo discurs del temps se ha anat polint y enriquint, com la castellana, puix te tambe disposicio pera rebre lo adorno que a la de Castella li comunica la llatina, de qui ha pres lo candor, esplendor, ostenta i molts més, de que tambe pot valerse la nostra llengua (Ortí i640: f.2r.)

Si els models de la llengua escrita prefiguren arreu una idea concreta de la llengua, que és compartida en la mesura que són acceptats i usats aquests models, i també prefiguren el rang i la relació de cada llengua respecte de les altres, quan en determinats llocs i moments de l'alta edat mitjana aparegui una necessitat social d'alteritat

Caplletra 71 (Tardor, 2021), p. 175-200 
Francesc Feliu

Els discursos fundacionals sobre el català

respecte de l'univers cultural llatí, quan sorgeixi un interès, en certes comunitats, per representar-se de forma separada, l'escriptura del vulgar serà un element decisiu, al marge de si el vulgar parlat ha canviat més o menys respecte d'un moment anterior. ${ }^{28}$

La combinació dels tres elements que he esmentat — la tendència de les parles individuals a anivellar-se quan hi ha contacte, la mudable consciència lingüística dels parlants, condicionada pel seu context històric i cultural, i la representació material de la llengua, que permet objectivar-ne l'existència i avançar en un camí de diferenciació (però regulada i sistemàtica, no caòtica) — permet construir, doncs, un relat diferent sobre el naixement del català, amb arrels en la sociolingüística i en la lingüística teòrica, que ha estat elaborat i difós sobretot per Josep Maria Nadal (1992a, 1999, etc.), a la llum d'algunes contribucions rellevants dels fundadors de l'anomenada sociolingüistica històrica (Richter 1975, Romaine 1982, Wright 1982). Jordi Mascarella (2009), en la seva brillant introducció a un llibre sobre el naixement del francès — sobre els Juraments d'Estrasburg! — ha resseguit amb més detalls els termes d'aquest nou paradigma, i de la crítica que porta implícita als plantejaments de la lingüística històrica convencional. La vella batalla dialèctica de Biondo contra Bruni no és pas morta del tot, i les posicions de l'aretí troben encara, d'alguna manera, qui les defensa.

Francesc Feliu

Institut de Llengua i Cultura Catalanes - Universitat de Girona

francesc.feliu@udg.edu

ORCID oooo-0003-1329-7328

\section{REFERÈNCIES BIBLIOGRÀFIQUES}

Alart, Julià Bernat (I88I) Documents sur la langue catalane des anciens comtés de Roussillon et de Cerdagne, París, Maisonneuve.

Alcover, Antoni Maria (1908) «La llengua catalana té sintacsis pròpia», Primer Congrés Internacional de la Llengua Catalana, p. 350-399.

Asperti, Stefano (2006) Origini romanze. Lingue, testi antichi, letterature, Roma, Viella.

28. El procés esmentat, pel qual uns determinats models d'escriptura vulgar esdevenen referents de representació de les comunitats de parlants és un procés lent, que es consolida més enllà de les primeres temptatives d'escriptura del vulgar. Seguint aquest raonament, els primers textos romànics difícilment poden atribuir-se a cap llengua concreta. Aquesta idea subjau en el documentadíssim llibre de Stefano Asperti (2006). 
Francesc FeLiu

Els discursos fundacionals sobre el català

BADIA i Margarit, Antoni Maria (I955) Fisiognómica comparada de las lenguas catalana y castellana, Barcelona, Real Academia de Buenas Letras de Barcelona.

- (1980) «L'Alt Urgell i el català occidental naixent», dins Actes del Cinquè Col-loqui Internacional de Llengua $i$ Literatura Catalanes, Barcelona, Publicacions de l'Abadia de Montserrat, p. 349-377.

- (I98I) La formació de la llengua catalana, Barcelona, Publicacions de l'Abadia de Montserrat.

BAstardas, Joan (I995a) "Quan el llatí esdevingué català», dins La llengua catalana mil anys enrere, Barcelona, Curial, p. 73-IO5.

- (I995b) «El català preliterari», dins La llengua catalana mil anys enrere, Barcelona, Curial, p. I09-I45.

BASTERo, Antoni de (I724) La Crusca provenzale, ovvero le voci, frasi, forme e maniere di dire che la gentilissima e celebre lingua toscana ha preso dalla provenzale, arricchite e illustrate e difese con motivi, con autorità e con esempj, Roma, Antonio de Rossi.

Bernat i Baltrons (2009), "Francesc Cambouliu, un pioner de la història de la literatura catalana», Anuari Verdaguer, I7, p. II-28.

Borst, Arno (1957-1963) Der Turmbauvon Babel Geschichte der Meinungen über Sprung und Vielfalt der Sprachen und Völker, Stuttgart, Anton Hiersemann.

CalçA, Francesc (I588) De Catalonia Liber Primus, Barcelona, Jaume Cendrat.

Cañellas, Mateu (2018) Sa llengo de sa Pàtria Mallorquina: s’herència des Rum, Independently published.

Colón, Germà (1976) El léxico catalán en la Romania, Madrid, Gredos.

Comellas, Pere (2020) «Parlem en llatí? Més aviat en poti-poti», Vilaweb, 3I-08-2020.

Coromines, Joan (1954) Elques'ha de saber de la llengua catalana, Palma, Editorial Moll.

Cortez, Yves (2007) Le français ne vient pas du latin! Essai sur une aberration linguistique, París, l'Harmattan.

Delcor, Maties (1985) «Les prêtres érudits du Roussillon aux XIxe et xxe siècles», Revue d'histoire de l'Église de France, I86, p. 25-46.

Escolano, Gaspar (16ro) Década primera de la historia de la insigne y coronada ciudad $y$ reino de Valencia, València, Pedro Patricio Mey.

Fauchet, Claude (I58I) Recueil de l'origine de la langue et poesie françoise, ryme et romans, París, Mamert Patisson.

Feliu, Francesc (1997) Antoni de Bastero. Història de la llengua catalana, Girona / Vic, Eumo Editorial.

- (20I4) «Els mites de la llengua», eHumanista/IVITRA, 6, p. I37-I49.

- (2019) «The persistence of 'old language' and the structuring of language communities», dins The Intricacy of Languages [Francesc Feliu \& Olga Fullana, eds.], Amsterdam / Filadèlfia, John Benjamins, p. 47-52.

Caplletra 71 (Tardor, 2021), p. 175-200 
Francesc Feliu

Els discursos fundacionals sobre el català

Feliu, Francesc, Josep Maria Nadal \& Joan Ferrer (202I, en premsa) «El concepte de llengua antiga», dins Gramàtica del català antic. [Josep Martines, Manel Pérez-Saldanya i Gemma Rigau, dirs.]

Ferrando, Antoni (1980) Consciència idiomàtica i nacional dels valencians, València, Universitat de València.

— (2000) «El paper dels primers editors (I473-I523) en la fixació del català modern», Caplletra, 27, p. 109-136.

Fuster, Joan (1984) «Notes sobre el "llemosí" a la València del segle XVI», dins Doctor Honoris Causa Joan Fuster Ortells, Bellaterra, Universitat Autònoma de Barcelona. [Reproduït després dins Llibres i problemes del Renaixement, València / Barcelona, Institut de Filologia Valenciana / Publicacions de l'Abadia del Montserrat, 1989, p. 52-53]

Gascón, Carles \& Oliver Vergés (20I7) «L'acta de consagració de la catedral d'Urgell. Un fals del temps del bisbe Ermengol redactat entre IoI6 i ro24", Afers. Fulls de recerca i pensament, 86, p. 19I-220.

Ginebra, Jordi (202I, en premsa) «Ideologia nacional i política lingüística: el discurs dels àngels i el discurs dels humans», dins Desired language [Francesc Feliu, ed.], Amsterdam / Filadèlfia, John Benjamins.

Grandia, Marià (I9OI) Gramática etimològica catalana, Barcelona, Llibreria Salesiana. Green, John N. (1990) «Romance Languages», dins Bernard Comrie (ed.), The Major Languages of Western Europe, Londres, Routledge.

Jiménez Huertas, Carme (2016) No venimos del latín. Edición revisada y ampliada, Las sandalias de Mercurio.

Mascarella, Jordi (2009) «Les llengües en temps de l'escriptura», dins Bernard Cerquiglini, El naixement de la llengua francesa [edició catalana de Jordi Mascarella], Girona, CCG Edicions, p. 7-39.

Meyer-Lübke, Wilhelm (1925) Das Katalanische. Seine Stellung zum Spanischen und Provenzalischen, Heidelberg, Carl Winter [versió catalana a Guillem Calaforra, Wilhelm Meyer-Lübke i "Das Katalanische", Barcelona, Institut d'Estudis Catalans, 1998]

Moran, Josep (2006) «El procés de creació del català escrit», dins Philip D. Rasico, El català antic, Girona, CCG Edicions, p. 7-48.

Moran, Josep \& Joan Anton Rabella (200I) Primers textos de la llengua catalana, Barcelona, Edicions Proa.

Mourelle de Lema (1982) «El valenciano, lengua autóctona», Thesaurus. Boletín del instituto Caro y Cuervo, 37 (2), p. 255-267. 
Francesc FeLiu

Els discursos fundacionals sobre el català

NADAL, Josep Maria (I992a) «Els orígens de la llengua catalana», dins Llengua escrita i llengua nacional, Barcelona, Quaderns Crema, p. 45-54.

- (1992b) «La ideologia lingüística de la nova Europa: De Dante a la fi del segle XV», dins Llengua escrita i llengua nacional, Barcelona, Quaderns Crema, p. 67-IOI.

- (I992C) "Artificiositat i alienació lingüística al segle XVI», dins Llengua escrita $i$ llengua nacional, Barcelona, Quaderns Crema, p. IO3-I55.

- (1999) "Són les llengües semblants a les aigües del mar: Normativa i història de la llengua", dins Estudis de Filologia Catalana. Dotze anys de l'Institut de Llengua $i$ Cultura Catalanes, Barcelona, Publicacions de l'Abadia del Montserrat, p. 9-27.

- (2005) La llengua sobre el paper, Girona, CCG Edicions.

- (2012) "I si escric llengua, veus? El dolor em trenca l'ànima» Per què vivim les llengües amb tanta passió?, Barcelona, Institut d'Estudis Catalans.

Nadal, Josep Maria \& Modest Prats (1982) Història de la llengua catalana I. Dels orígens fins al segle xv, Barcelona, Edicions 62.

Nicolás, Miquel (1998) La història de la llengua catalana: la construcció d'un discurs, València / Barcelona, Institut Interuniversitari de Filologia Valenciana / Publicacions de l'Abadia de Montserrat.

— (20II) «Hi ha una història social de la llengua catalana?, Treballs de Sociolingüistica Catalana, 2I, p. IO5-II4.

Ortí, Marc Antoni (I640) Siglo quarto de la conquista de Valencia, València, Juan Bautista Marçal.

Pers i Ramona, Magí (i854) Historia de la lengua y de la literatura catalana, desde su origen hasta nuestros dias, Barcelona, Imprenta de José Tauló.

RADATZ, Hans-Ingo (20I2) "Per què els elements gal.loromànics fan "heavy" en català. Arran del clàssic debat sobre la subagrupació del català», eHumanista/IVITRA, 2, p. 202-2I8.

RAFANELl, August (I99Ia) Un nom per a la llengua. El concepte de llemosí en la història del català, Girona / Vic, Eumo Editorial.

- (I99rb) «El llemosinisme valencià a la darreria del segle XIX», Caplletra, II, p. 35-50.

- (1993) «El mossàrab i la llengua dels valencians», Revista de Catalunya, 79, p. 3I-54.

- (2000) El català modern, Barcelona, Editorial Empúries.

- (2006) La il.lusió occitana, Barcelona, Quaderns Crema, 2 vol.

Rafanell, August \& Albert Rossich (2000) «La langue occitane dans la Catalogne du Xvine siècle», Lengas: Revue de sociolinguistique, 48, p. 45-65.

Rasico, Philip D. (1986) «Consideracions fonològiques sobre el parlar de l'Alt Urgell a l'Edat Mitjana", dins Actes del Setè Col-loqui Internacional de Llengua i Literatura Catalanes, Barcelona, Publicacions de l'Abadia de Montserrat, p. 44I-465. 
Francesc Feliu

Els discursos fundacionals sobre el català

Richter, Michael (1975) "A Sociolinguistic Approach to the Latin Middle Ages», Studies in Church History, II, p. 69-82.

Riquer, Martí de (1964) Història de la literatura catalana, vol. I, Barcelona, Ariel.

Romaine, Suzanne (1982) Socio-Historical Linguistics. Its Status and Methodology, Cambridge, Cambridge University Press.

Ros, Carles (1734) Epitome del origen y grandezas del idioma valenciano, València, Cosme Granja.

Russell-Gebbett, Paul (1965) Mediaeval Catalan Linguistic Texts, Oxford, The Dolphin Book.

Schmid, Beatrice (1988) Les "traduccions valencianes" del 'Blanquerna' (València I52I) i de la 'Scala Dei' (Barcelona I523), Barcelona, Curial / Publicacions de l'Abadia de Montserrat.

Ubieto, Antonio (1979) Origenes del Reino de Valencia. Cuestiones cronológicas sobre su reconquista, Saragossa, Anubar.

Valsalobre, Pep (2002) Agusti Eura. Obra poètica i altres textos. Barcelona, Fundació Pere Coromines (Autors catalans Antics, 13)

VÀrvaro, Alberto (1988) Historia, problemas y métodos de la lingüistica románica, Barcelona, Sirmio. [Original italià publicat en 1968 a Liguori Editore.]

VICTORRI, Bernard (2006) «À la recherche de la langue originelle», dins Jean-Louis Dessalles, Pascal Picq \& Bernard Victorri, Les origines du langage, París, Le Pommier, p. 75-I3I.

Wright, Roger (1982) Late Latin and Early Romance in Spain and Carolingian France, Liverpool, Francis Cairns. 